\title{
RESEARCH
}

\section{RETROSPECTIVE ANALYSIS OF COST AND FACTORS AFFECTING MORTALITY IN ELDERLY PATIENTS IN THE INTENSIVE CARE UNIT}

Turkish Journal of Geriatrics

DOI: 10.31086/tigeri.2020.137

2020; 23(1): 51-59

- Ilim IRMAK ${ }^{1}$ (D)

n Nalan ADIGUZEL ${ }^{2}$ (D)

- Eylem TUNCAY ${ }^{2}$

- Feyza KARGIN² (D)

- Ozlem YAZICIOGLU MOCIN² (D)

- Gokay GÜNGOR ${ }^{2}$ D

- Zuhal KARAKURT²

CORRESPONDANCE

İim IRMAK

Hacettepe University Faculty of Medicine

Department of Chest Diseases, Ankara,

TURKEY

Phone: +905056801803

e-mail: ilimirmak@hotmail.com

Received: 25/11/2019

Accepted: 17/12/2019

\section{Abstract}

Introduction: The older population of the world continues to grow. Currently, $8.5 \%$ of people worldwide are above 65 years, leading to an increased frequency of intensive care unit admission. This study aimed to assess the cost and factors affecting mortality in elderly patients.

Materials and Methods: This retrospective cohort study included patients aged over 65 years admitted to the tertiary intensive care unit. The demographics including age, gender, body mass index, comorbidities, Glasgow coma scale scores, acute physiology and chronic health evaluation II, the Charlson comorbidity index scores, diagnosis, blood gas analysis results, type of mechanical ventilation, length of stay in the intensive care unit (ICU), time of death and cost of ICU stay were obtained from the government electronic mortality declaration system.

Results: This study evaluated 1401 patients with a mean age of $75.73 \pm 6.92$, where the mean BMI was $25.31 \pm 7.03$. Most of the patients $(n=714,51 \%)$ belonged to the $65-75$ years old group while $569(40.6 \%)$ belonged to the $75-85$ years old group and $118(8.4 \%)$ were over 85 years old. Mortality rates were the following: 28-day mortality rate, $41.7 \%$; 1 -year mortality rate, $66.4 \%$ and 2-year mortality rate, $75 \%$. The mean cost of ICU stay was $7992.95 \pm 10166.33$, and the mean cost of hospital stay was $8211.28 \pm 10172.41$ も.

Conclusion: It is shown that comorbidities increased as age advanced, and sepsis remains the leading cause of death in short-term and long-term periods in the elderly population admitted to the ICU. Aged.

Keywords: Critical Care; Sepsis; Comorbidity; Mortality; Mechanical Ventilation;

${ }^{1}$ Hacettepe University Faculty of Medicine, Department of Chest Diseases, Ankara, TURKEY.

${ }^{2}$ Health Sciences University Sureyyapasa Chest Diseases and Thoracic Surgery Training and Research Hospital, Intensive Care Unit, Istanbul, TURKEY. 


\section{INTRODUCTION}

Technological advancements and improved health care resulted in increasing human lifespan. Therefore, the world population is progressively getting older. The admission of elderly and very elderly patients to the intensive care unit (ICU) has increased in developed countries (1). The short-term outcomes after ICU may be associated with illness severity, comorbidities, performance status of the patient and the quality of care. Despite previous studies, 'age' effect remains to be a debate where health-care professionals are still reluctant in admitting the elderly to the ICU (2). The severity of illness is the leading predictor of mortality rates in the ICU, ranging between 6.4 and $40 \%$ in different ICUs. Several studies focus on 30-day mortality, where 1-year and 2-year mortality rates seem to be more relevant. The discharge from the ICU of the elderly appears to be the beginning of the treatment strategy, since it is most likely crucial to hold the elderly outside of the ICU (3).

Moreover, ICU stay was seven times longer in patients above 75 years of age than in patients aged 65 years, and mechanical ventilation requirement was reported to be 10 times higher in patients over 85 years than in patients below 55 years $(4,5)$. Besides the challenging medical care of the elderly, ICU cost accounts for $20-30 \%$ of hospital care costs. Several questions remain unanswered, such as the controversial benefit of ICU care for the elderly.

This study primarily aimed to evaluate the clinical characteristics and outcome in elderly patients, and the secondary goal was to define the independent predictors of ICU mortality. Lastly, particular focus was on medico-economic implications.

\section{MATERIALS AND METHODS}

This retrospective cohort study was approved by the Scientific Study Committee by a Health Sciences University Chest Diseases and Thoracic Surgery Training and Research Hospital Ethics Committee
(Date, 30.04.2019/ No: 066), and patients above 65 years admitted to the tertiary ICU between October 2014 and October 2016 were enrolled in this study.

\section{Data}

Patient's data were collected from the hospital database. Age, gender, body mass index (BMI), comorbidities, Glasgow coma scale (GCS) score, acute physiology and chronic health evaluation (APACHE) II scores, the Charlson comorbidity in$\operatorname{dex}(\mathrm{CCl})$ score, diagnosis, blood gas analysis results, type of mechanical ventilation (MV) applied in intensive care unit (invasive or noninvasive), length of ICU stay, time of death and cost of ICU stay were obtained from the government electronic mortality declaration system.

\section{Statistical Analysis}

The distribution of the variables was analysed using Kolmogorov-Smirnov test, and the quantitative data were presented as mean and standard deviation where qualitative data were given as median (interquartile range [IOR] 25\%-75\%) values and also with numbers and percentage. The relationship between variables was determined using either Pearson ( $r$ ) or Spearman's $(\rho)$ correlation analysis. Long-term mortality risk factors were analysed by multivariate regression analysis, and the age groups and type of MV were compared by one-way ANOVA test. Intragroup comparisons were analysed using Tukey's HSD test. Independent samples t-test was used to compare the GCS, $\mathrm{CCl}$ and APACHE II scores. Categorical data was analysed using chi-square test. Data were statistically analysed using the Statistical Package for Social Sciences (SPSS) version 20 programme. The significance level was determined to be $p<0.05$.

\section{RESULTS}

This study included 1401 patients. Figure 1 shows the recruitment of the patients. The mean age of the patients was $75.73 \pm 6.92$, where the mean BMI 
Figure 1. Flow chart of the study.
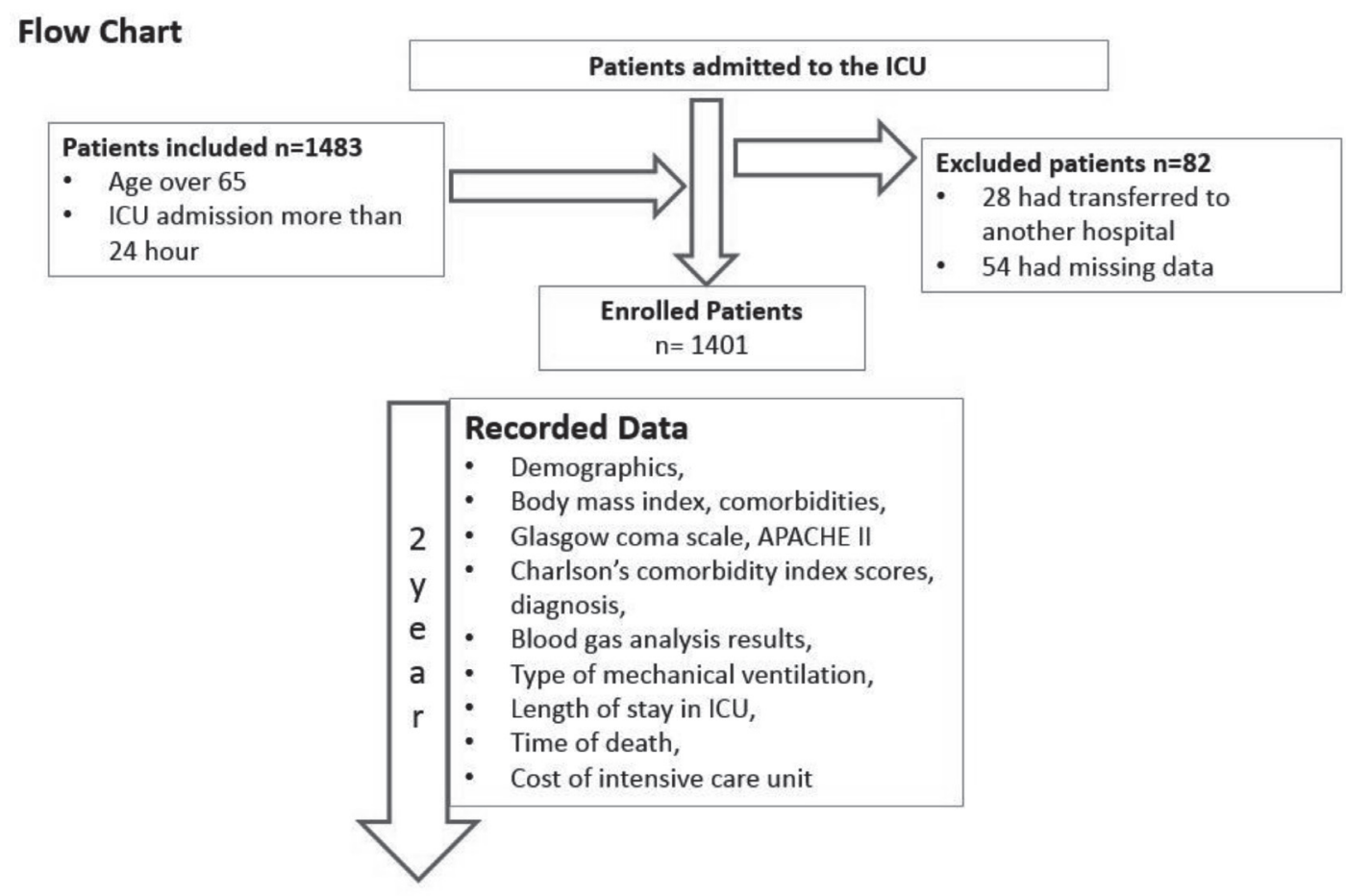

Follow-up period: 1 and 2 mortality

was $25.31 \pm 7.03$. Most of the patients ( $n=714,51 \%)$ belonged to the 65-75 years old group, while 569 (40.6\%) belonged to the 75-85 years old group and 118 patients (8.4\%) were over 85 years old. The diagnosis of the patients on admission were the following: pulmonary diseases ( $n=1058,75.5 \%)$, cardiac diseases $(n=778,55.5 \%)$, renal diseases $(n=398,28.4 \%)$ and neurological diseases ( $n=350$, 25\%). Majority of the patients were referred from the emergency room (ER) ( $n=705,50.3 \%)$, where chest disease was the second one $(n=581,41.5 \%)$. Table 1 presents the medical characteristics of the patients. The mean ICU stay was $9.63 \pm 8.45$ days, with a minimum of 1 and a maximum of 57 days.
The patients' mean survival time starting with the day admitted to the ICU was $374.31 \pm 497.98$ days with a minimum value of 1 and a maximum of 1935 days. A total of 497 (35.5\%) of the patients died in the ICU, and 904 (64.5\%) died after discharge. Table 2 shows the comparison of the GCS and APACHE II and $\mathrm{CCl}$ scores of patients who died in the ICU and after discharge. A positive weak correlation was detected between age and $C C l$ score $(B=0.340$, $\mathrm{p}<0.001)$. The frequency of comorbidities among the age groups is shown in Table 3. A multivariate regression analysis of the age; presence of any of the comorbidities including pulmonary diseases $(P D)$, cardiac diseases (CD), neurological diseases 
Table 1. Characteristics of the patients.

\begin{tabular}{|c|c|c|c|}
\hline & Mean \pm SD & Median & IOR \\
\hline Age (years) & $75.73 \pm 6.92$ & 75 & 11 \\
\hline BMI (kg/m2) & $25.31 \pm 7.03$ & 23 & 8 \\
\hline $\mathrm{CCl}$ score & $5.45 \pm 1.62$ & 5 & 2 \\
\hline APACHE II score & $25.92 \pm 8.03$ & 24 & 11 \\
\hline \multirow[t]{2}{*}{ GCS score } & $12.29 \pm 4.24$ & 15 & 4 \\
\hline & Hypoxia (n, \%) & $\begin{array}{r}\text { Hypoxia + Hypercarbia } \\
(\mathrm{n}, \%)\end{array}$ & $\begin{array}{r}\text { Metabolic disturbance (n, } \\
\%)\end{array}$ \\
\hline Type of BGA & $420(30 \%)$ & 826 (59\%) & 155 (11\%) \\
\hline
\end{tabular}

BMI, body mass index; CCl, Charlson comorbidity index; APACHE, acute physiology and chronic health evaluation; GCS, Glasgow coma scale; BGA, blood gas analysis.

Table 2. APACHE II, CCl, and GCS score comparisons.

\begin{tabular}{|l|r|r|r|}
\hline & Patients died in ICU & Patients died after & p \\
\hline APACHE II score & $30.87 \pm 8.05$ & $23.2 \pm 6.59$ & $<0.001^{\star}$ \\
\hline CCI score & $5.98 \pm 1.78$ & $5.16 \pm 1.44$ & $<0.001^{*}$ \\
\hline GCS score & $10.58 \pm 4.82$ & $13.23 \pm 3.56$ & $<0.001^{*}$ \\
\hline
\end{tabular}

${ }^{*} p<0.05$. Independent samples $t$ test.

(ND), renal diseases (RD), malignancy, mechanical ventilation (no MV, NIMV or IMV), ARDS, sepsis, hypertension and diabetes mellitus as possible predictors of survival time starting from ICU admission to the time of death in the ICU; 28-day mortality; 1 -year mortality and 2-year mortality is displayed in Table 4. A positive moderate correlation was noted between APACHE II score and ICU mortality, while a negative moderate correlation was observed between APACHE II score and survival time $(\rho=0.458$, $p<0.001 ; \rho=-0.461, p<0.001$, respectively). A positive weak was detected between $\mathrm{CCl}$ and ICU mortality, and a negative weak correlation was found between $\mathrm{CCl}$ and survival time $(\rho=0.232, p<0.001$; $\rho=-0.282, \quad p<0.001$, respectively). Moreover, a negative weak correlation was observed between GCS on admission and ICU mortality, while a positive weak correlation was noted between GCS on admission and survival time $(\rho=-0.318, p<0.001$; $\rho=0.354, p<0.001$, respectively). Table 5 displays the relationship between MV and age groups and scores. Mortality rates were found in the following order: 28 -day mortality rate, $41.7 \%$; 1 -year mortality rate, $66.4 \%$ and 2 -year mortality rate, $75 \%$. Patients with $\mathrm{MV}$ had a mortality rate of $40.5 \%$ in 28 days, $62.5 \%$ in 1 year and $70.2 \%$ in 2 years. The costs of hospital and ICU stay according to age groups are summarised in Table 6. The mean cost of ICU stay was $7992.95 \pm 10166.33 k$, and the mean cost of hospital stay was $8211.28 \pm 10172.41$. 
Table 3. The distribution of comorbidities among age groups.

\begin{tabular}{|c|c|c|c|c|c|}
\hline & $\begin{array}{r}\text { Total } \\
(n=1401) \\
n(\%)\end{array}$ & $\begin{array}{r}65-75 \text { years } \\
(n=714) \\
n(\%)\end{array}$ & $\begin{array}{r}75-85 \text { years } \\
(n=714) \\
n(\%)\end{array}$ & $\begin{array}{r}>85 \text { years } \\
(n=714) \\
n(\%)\end{array}$ & $\mathbf{p}$ \\
\hline PD & $1058(75.5)$ & $574(80.4)$ & 418 (73.5) & $66(55.9)$ & $<0.001$ * \\
\hline$C D$ & 778 (55.5) & $361(50.6)$ & 337 (59.2) & $80(67.8)$ & $<0.001$ * \\
\hline ND & $350(25)$ & $133(18.6)$ & $169(29.7)$ & $48(40.7)$ & $<0.001^{*}$ \\
\hline RD & 398 (28.4) & $172(24.1)$ & 178 (31.3) & $48(40.7)$ & $<0.001^{\star}$ \\
\hline Malignity & $241(17.2)$ & $159(22.3)$ & 75 (13.2) & $7(5.9)$ & $<0.001^{*}$ \\
\hline MV & 1295 (92.4) & $667(93.4)$ & $523(91.9)$ & $105(89)$ & 0.221 \\
\hline ARDS & $39(2.8)$ & $24(3.4)$ & $11(1.9)$ & $4(3.4)$ & 0.262 \\
\hline Sepsis & $384(27.4)$ & $182(25.5)$ & $171(30.1)$ & $31(26.3)$ & 0.185 \\
\hline DM & $379(27.1)$ & 199 (27.9) & $151(26.5)$ & $29(24.6)$ & 0.708 \\
\hline HT & 785 (56) & 373 (52.2) & 331 (58.2) & 81 (68.6) & $0.001^{*}$ \\
\hline
\end{tabular}

${ }^{*} p<0.05$.

Chi-square test. PD, pulmonary diseases; CD, cardiac diseases; ND, neurological diseases; RD, renal diseases; MV, mechanical ventilation; ARDS, acute respiratory distress syndrome; $\mathrm{DM}$, diabetes mellitus; $\mathrm{HT}$, hypertension.

Table 4. Multivariate regression analysis.

\begin{tabular}{|c|c|c|c|c|}
\hline & $\begin{array}{r}\text { Mortality in ICU } \\
(B, p)\end{array}$ & $\begin{array}{r}\text { 28-days mortality } \\
((\beta, p)\end{array}$ & $\begin{array}{r}1-y e a r \text { mortality } \\
((B, p)\end{array}$ & $\begin{array}{r}\text { 2-years mortality } \\
((\beta, p)\end{array}$ \\
\hline Age (years) & - & $0.038,0.088$ & $0.093,<0.001^{*}$ & $0.069,0.007$ \\
\hline PD & $-0.106,<0.001^{*}$ & $-0.097,<0.001^{\star}$ & $-0.055,0.034^{\star}$ & $-0.051,0.059$ \\
\hline$C D$ & $0.043,0.044^{*}$ & $0.061,0.008^{\star}$ & - & - \\
\hline ND & - & $0.061,0.008^{*}$ & $0.123,<0.001^{\star}$ & $0.095,<0.001^{*}$ \\
\hline RD & $0.267,<0.001^{*}$ & $0.255,<0.001^{\star}$ & $0.173,<0.001^{*}$ & $0.144,<0.001^{*}$ \\
\hline Malignity & $0.120,<0.001^{*}$ & $0.128,<0.001^{*}$ & $0.185,<0.001^{\star}$ & $0.160,<0.001^{*}$ \\
\hline MV & $0.121,<0.001 *$ & $0.105,<0.001 *$ & $0.073,0.002^{\star}$ & $0.060,0.018^{\star}$ \\
\hline ARDS & $0.051,0.017^{*}$ & $0.054,0.014^{\star}$ & - & - \\
\hline Sepsis & $0.365,<0.001^{\star}$ & $0.351,<0.001^{*}$ & $0.241,<0.001^{\star}$ & $0.191,<0.001^{*}$ \\
\hline DM & - & - & $-0.045,0.055$ & - \\
\hline HT & $-0.048,0.028 *$ & $-0.076,0.001^{*}$ & - & - \\
\hline
\end{tabular}

${ }^{*} p<0.05$. PD, pulmonary diseases; $C D$, cardiac diseases; $N D$, neurological diseases; RD, renal diseases; MV, mechanical ventilation; ARDS, acute respiratory distress syndrome; DM, diabetes mellitus; HT, hypertension. Death in ICU: The model explained $62.1 \%$ of the variance $(F=109.327, p<0.001)$.

28-days mortality: The model explained $61.4 \%$ of the variance ( $F=84.074, p<0.001)$. 1-year mortality: The model explained $47.6 \%$ of the variance ( $F=50.914, p<0.001)$. 2-years mortality: The model explained $38.7 \%$ of the variance $(F=35.116, p<0.001)$.

acute respiratory distress syndrome; DM, diabetes mellitus; $\mathrm{HT}$, hypertension. 
Table 5. The effect of mechanical ventilation on the scores and survival time.

\begin{tabular}{|c|c|c|c|c|}
\hline & $\begin{array}{l}\text { No MV } \\
(n=106\end{array}$ & $\begin{array}{r}\text { NIMV } \\
(n=516)\end{array}$ & $\begin{array}{r}\text { IMV } \\
(n=779) \\
\end{array}$ & $\mathbf{p}$ \\
\hline $65-75$ years & 47 (6.6\%) & 277 (38.8\%) & 390 (54.6\%) & \multirow{3}{*}{0.443} \\
\hline $75-85$ years & 46 (8.1\%) & 192 (33.7\%) & 331 (58.2\%) & \\
\hline$>85$ years & $13(11 \%)$ & 47 (39.8\%) & $58(49.2 \%)$ & \\
\hline $\begin{array}{l}\text { Stay in ICU } \\
\text { (days) }\end{array}$ & $5.34 \pm 4.99$ & $7.26 \pm 5.19$ & $11.79 \pm 9.81$ & $<0.001^{*}$ \\
\hline $\begin{array}{l}\text { Survival time } \\
\text { (days) }\end{array}$ & $557.3 \pm 551.14$ & $576.35 \pm 533.44$ & $215.38 \pm 399.86$ & $<0.001^{*}$ \\
\hline GCS score & $13.66 \pm 2.95$ & $14.4 \pm 1.84$ & $10.71 \pm 4.82$ & $<0.001^{*}$ \\
\hline $\mathrm{CCl}$ score & $5.37 \pm 2.04$ & $5.14 \pm 1.44$ & $5.67 \pm 1.63$ & $<0.001^{*}$ \\
\hline APACHE II score & $21.11 \pm 5.96$ & $21.3 \pm 5.08$ & $29.64 \pm 7.93$ & $<0.001^{*}$ \\
\hline
\end{tabular}

${ }^{*} \mathrm{p}<0.05$. One-way ANOVA test. Tukey's HSD test.

Intragroup comparisons for the stay in ICU: No MV-NIMV ( $p=0.066)$; No MV-IMV $(p<0.001)$; NIMV-IMV $(p<0.001)$.

Intragroup comparisons for survival time: No MV-NIMV ( $=0.922)$; No MV-IMV $(p<0.001)$; NIMV-IMV (p<0.001).

Intragroup comparisons for GCS score: No MV-NIMV ( $p=0.165)$; No MV-IMV ( $p<0.001)$; NIMV-IMV $(p<0.001)$.

Intragroup comparisons for CCI score: No MV-NIMV ( $p=0.352)$; No MV-IMV ( $p=0.177)$; NIMV-IMV $(p<0.001)$

Intragroup comparisons for APACHE II score: No MV-NIMV ( $p=0.963)$; No MV-IMV ( $<<0.001)$; NIMV-IMV ( $<<0.001)$.

Table 6. The cost distribution according to the use of mechanical ventilation.

\begin{tabular}{|l|r|r|r|c|}
\hline & $\begin{array}{r}\text { No MV } \\
(\mathbf{n = 1 0 6}\end{array}$ & $\begin{array}{r}\text { NIMV } \\
(\mathbf{n = 5 1 6 )}\end{array}$ & $\begin{array}{r}\text { IMV } \\
(\mathbf{n = 7 7 9 )}\end{array}$ & $\mathbf{p}$ \\
\hline $\begin{array}{l}\text { Cost of Hospital } \\
\text { Stay }\end{array}$ & $4421.97 \pm 5130.9$ & $6651.16 \pm 7824.3$ & $9511.85 \pm 11459.14$ & $<0.001^{\star}$ \\
\hline Cost of ICU stay & 4854.578460 .27 & $5422.69 \pm 6245.22$ & $9096.85 \pm 10692.66$ & $<0.001^{\star}$ \\
\hline
\end{tabular}

${ }^{*} \mathrm{p}<0.05$. One-way ANOVA test. Tukey's HSD test.

Intragroup comparisons for cost of hospital stay:

No MV-NIMV ( $p=0.313)$; No MV-IMV ( $p=0.002)$; NIMV-IMV ( $p=0.001)$.

Intragroup comparisons for cost of ICU stay: No MV-NIMV ( $p=0.850)$; No MV-IMV ( $p<0.001)$; NIMV-IMV $(p<0.001)$.

\section{DISCUSSION}

This study showed that PD, CD and HT are the leading cause of ICU admission among the elderly population, where $C D, N D, R D$ and $H T$ have increased with the advancing age and PD and malignancy decreased. The evident causes of death in the ICU appears to be RD and sepsis, those are the same in 28-days. Moreover, 1-year and 2-year mortality were considerably associated with sepsis, RD and malignancy in the elderly population in the ICU. Patients with NIMV had a longer survival compared to patients with IMV or without MV. However, MV (NIMV or IMV) lengthened ICU stay and increased the cost of hospital and ICU stay. It is also detected that higher APACHE II score was associated with increased ICU mortality rate and longer survival time. Life expectancy has increased in the developed countries, raising the number of ICU admissions. The prognosis prediction of the elderly in the ICU has been investigated by sev- 
eral studies, including that of Somme et al. that showed the intensity of the illness evaluated by APACHE II score could be the most important predictor in short-term mortality in elderly patients. The authors also reported that age and limited daily activities might be the possible predictors of the long-term mortality (5). Several studies reported the same result; that is, severity of the illness was the only predictor for short-term mortality $(1,6,7)$. Despite the abovementioned studies, recent analysis conducted on large populations demonstrated that the medical condition of the patient in the hospital is more likely associated with in-hospital death rather than age (8). Moreover, Flaatten et al. showed that age had a minimal effect on ICU survival (9). This study revealed that considering the age as a single variable in the equation could be an underestimation compared to the condition of the patient associated with diseases they had. However, age is a factor indirectly affecting the observed frequency of the disease, leading a change on the balance by a path that did not exist in the account. Studies have demonstrated that ageing is associated with an increased susceptibility to PD $(10,11)$. Despite the study's limited sample population, it was shown that PD and malignancy frequency decreased related to advancing age. This outcome could be associated with the low number of patients $>85$ years of age, which might be higher than the sum of the patients in the 75-85 years and $>85$ years groups. In contrast, advanced age is evidently related to malignancy. This is also confirmed by the present study (11). Inevitably, life expectancy is shorter in a patient diagnosed with cancer who also requires ICU treatment associated with accompanying disorders, and age is also related to prolonged MV in the elderly (12).

Furthermore, physiologic changes may occur in the cardiovascular system of elderly patients. Stage 1 diastolic dysfunction is a normal alteration of ageing. Left ventricular outflow may be depleted under stress conditions by a change in the structural integrity of the ventricular space called 'sigmoid septum'. Ageing leads to reduced maximal cardiac output; decreased inotropy, lusotropy and chronotropy and lower tissue extraction of oxygen (13). Renal changes are mainly caused by the decreased extraction of sodium levels, triggering older patients to be more prone to volume fluctuations. Diminished baroreceptor sensitivity is also a negative factor for pressure control of the cardiovascular system. Moreover, ageing affects cognitive functions, resulting in difficulty in memory, executive functioning and processing speed. Immobility is another loss of functioning during ageing observed in $82 \%$ of the patients above 85 years. Immobility and sedentary lifestyle impair the physiologic changes on other systems. It is noted that early mobility and physical exercise are fundamental in improving the functionality of the elderly patients (14-16). This study demonstrated that the frequencies of $C D, N D, R D$ and $H T$ increased with advancing age, also noted in previous studies mentioned above.

Nevertheless, the overall ICU mortality was affected by sepsis, a known cause of death which is the most likely cause of admission and the most common cause of death in the ICU and has been currently indicated as the final common route to death from infection (17). It has a high mortality rate ranging from $11.9 \%$ to $47.2 \%$ (18). In this study, sepsis had the single factor associated with the overall, 28-day, 1-year and 2-year mortality with a higher correlation coefficient than the other variables including RD and malignity. Despite the development of detailed sepsis guidelines for those requiring early diagnosis and prompt administration of therapy to prevent single- or multiple-organ dysfunctions, sepsis remains to be the most challenging syndrome worldwide. Recent developments in the management of sepsis have decreased mortality rates by 20 to $30 \%$ in the last decades; however, complexity of therapy for sepsis results in high costs (19-21). Moreover, the treatment of elderly patients admitted to the ICU could be challenging due to various factors. This 
group of patients has a lower life expectancy, high mortality rates and high health-care costs, increasing with advancing age. In this study, the mortality rates were $41.7 \%, 66.4 \%$ and $75 \%$ in 28-day, 1-year and 2-year mortality, respectively. Higher mortality rates indicated that the severity of comorbidities accompanying complications in ICU could increase with advancing age. The bigger percentage of patients admitted to the ICU was comprised of elderly patients above 75 years. The use of recent technologies, which are also expensive, is increasing and expands the health-care costs accompanied by increased ICU admission (22).

The use of MV holds higher ICU costs (23). Similar to this information, this study showed that MV requirement extends the ICU and hospital stay that also increase cost. An interesting finding of this study is that MV seemed to shorten survival time; however, MV is a technique performed in respiratory failure. The lower survival time may be considerably associated with the severe comorbidities leading to the use of MV. Several studies have been conducted on the prediction of ICU mortality, resulting in a highly valuable scoring system called APACHE II (22). The relationship between APACHE II score and mortality and survival time in elderly patients is a known condition in which the APACHE II score defines the patient's mortality risk on admission.

\section{REFERENCES}

1. Martin-Loeches I, Guia MC, Vallecoccia MS et al. Risk factors for mortality in elderly and very elderly critically ill patients with sepsis: a prospective, observational, multicenter cohort study. Ann Intensive Care 2019; 9 (1): 26. (PMID:30715638).

2. Zampieri FG, Colombari F. The impact of performance status and comorbidities on the short-term prognosis of very elderly patients admitted to the ICU. BMC Anesthesiol 2014; 14: 59. (PMID:25071415).

3. Le Borgne P, Maestraggi $Q$, Couraud $S$ et al. Critically ill elderly patients ( $\geq 90$ years): Clinical characteristics, outcome and financial implications. PLoS One 2018; 13 (6): e0198360. (PMID:29856809).
Overall, this study showed the causes of ICU death by utilising the elderly population, the association between the advanced age and comorbidities and the effects of MV on the ICU stay and cost. These data provide baseline and local information that might be enhanced by gathering data from distinct hospitals and regional areas.

This study had some limitations. First, the blood gas analysis data could be obtained in detail provided there is additional information on the patient's condition; unfortunately, we were not able to obtain such data from the hospital database. Second, our data did not include the patient's functional status after discharge. Third, the admission policy variation across countries may lead to restrict the generalizability of the results.

Therefore, this study revealed that comorbidities increased along with advancing age, and sepsis is still the leading cause of death in short-term and long-term periods in the elderly population admitted to the ICU. Further studies with large sample size may be conducted to elucidate this outcome.

\section{CONFLICT OF INTEREST}

All authors declared that there is no conflict of interest.

4. Dinkci MD, Yuce Y, Cevik B, Erkal KH. Retrospective analysis of factors affecting intensive care unit mortality in patients over 75 years of age. Turkish Journal of Geriatrics 2017;20 (2): 91-99.

5. Somme D, Maillet JM, Gisselbrecht M, Novara A, Ract C, Fagon JY. Critically ill old and the oldestold patients in intensive care: short- and long-term outcomes. Intensive Care Med 2003; 29 (12): 21372143. (PMID:14614546).

6. de Rooij SE, Abu-Hanna A, Levi M, de Jonge E. Factors that predict outcome of intensive care treatment in very elderly patients: a review. Crit Care 2005; 9 (4): R307-314. (PMID:16137342). 
7. Vosylius S, Sipylaite J, Ivaskevicius J. Determinants of outcome in elderly patients admitted to the intensive care unit. Age Ageing 2005; 34 (2): 157-162. (PMID:15713860)

8. Boumendil A, Angus DC, Guitonneau AL et al.Variability of intensive care admission decisions for the very elderly. PLoS One 2012; 7 (4): e34387. (PMID:22509296)

9. Flaatten $\mathrm{H}, \mathrm{De}$ Lange DW, Morandi A et al. The impact of frailty on ICU and 30-day mortality and the level of care in very elderly patients ( $\geq 80$ years). Intensive Care Med 2017; 43 (12): 1820-1828. (PMID:28936626).

10. Guidet B, Leblanc G, Simon $T$ et al. Effect of Systematic Intensive Care Unit Triage on Long-term Mortality Among Critically III Elderly Patients in France: A Randomized Clinical Trial. JAMA 2017; 318 (15): 1450-1459. (PMID:28973065).

11. Vaz Fragoso CA. Epidemiology of Lung Disease in Older Persons. Clin Geriatr Med 2017; 33 (4): 491-501. (PMID:28991646)

12. Ely EW, Wheeler AP, Thompson BT, Ancukiewicz $M$, Steinberg KP, Bernard GR. Recovery rate and prognosis in older persons who develop acute lung injury and the acute respiratory distress syndrome. Ann Intern Med 2002; 136 (1): 25-36.(PMID:11777361).

13. Jackson CF, Wenger NK. Cardiovascular disease in the elderly. Rev Esp Cardiol 2011; 64 (8): 697-712. (PMID:21723657).

14. Deary IJ, Corley J, Gow AJ et al. Age-associated cognitive decline. Br Med Bull 2009; 92: 135-152. (PMID:19776035).

15. Axer $H$, Axer $M$, Sauer $H$, Witte OW, Hagemann $\mathrm{G}$. Falls and gait disorders in geriatric neurology. Clin Neurol Neurosurg 2010; 112 (4): 265-274. (PMID:20089351).
16. Groessl EJ, Kaplan RM, Rejeski WJ et al. Physical Activity and Performance Impact Long-term Quality of Life in Older Adults at Risk for Major Mobility Disability. Am J Prev Med 2019; 56 (1): 141-146. (PMID:30573142).

17. Perner A, Gordon AC, De Backer D et al. Sepsis: frontiers in diagnosis, resuscitation and antibiotic therapy. Intensive Care Med 2016; 42 (12): 1958-1969. (PMID:27695884).

18. Sakr $Y$, Jaschinski $U$, Wittebole $X$ et al. Sepsis in Intensive Care Unit Patients: Worldwide Data From the Intensive Care over Nations Audit. Open Forum Infect Dis 2018; 5 (12): ofy313. (PMID:30555852).

19. Rhodes A, Evans LE, Alhazzani Wet al. Surviving Sepsis Campaign: International Guidelines for Management of Sepsis and Septic Shock: 2016. Intensive Care Med 2017; 43 (3): 304-377. (PMID:28101605).

20. Gaieski DF, Edwards JM, Kallan MJ, Carr BG. Benchmarking the incidence and mortality of severe sepsis in the United States. Crit Care Med 2013; 41 (5): 1167-1174. (PMID:23442987).

21. Marik PE, Linde-Zwirble WT, Bittner EA, Sahatjian J, Hansell D. Fluid administration in severe sepsis and septic shock, patterns and outcomes: an analysis of a large national database. Intensive Care Med 2017; 43 (5): 625-632. (PMID:28130687).

22. Reyes JC, Alonso JV, Fonseca J, Santos ML, Jiménez Mde L, Braniff J. Characteristics and mortality of elderly patients admitted to the Intensive Care Unit of a district hospital. Indian J Crit Care Med 2016; 20 (7): 391-3977. (PMID:27555692).

23. Milbrandt EB, Eldadah B, Nayfield S, Hadley E, Angus DC. Toward an integrated research agenda for critical illness in aging. Am J Respir Crit Care Med 2010; 182 (8): 995-1003. (PMID:20558632). 